\title{
Ainda somos os mesmos?: representações midiáticas da juventude em movimentos sociais, ontem e hoje
}

\section{Are we still the same? Media representations of youth in social movements, yesterday and today}

\section{Cláudia da Silva Pereira}

Professora e pesquisadora do Programa de Pós-Graduação em Comunicação da PUC-Rio. <caupereira@gmail.com>

\section{RESUMO}

O objetivo deste artigo é analisar as representações midiáticas das juventudes que se manifestaram pelas ruas do Brasil em três importantes momentos políticos, datados em 1968, 1988-1992 e 2013. Uma pesquisa documental coletoumatérias de revista e jornal, Veja e O Globo, respectivamente, que foram escolhidos por serem os veículos de maior circulação, nos dois meios de comunicação, em todos os períodos abordados. As dez matérias foram encontradas a partir de buscas nos acervos digitais disponibilizados na internet, em que palavras-chave como "juventude", "revolta", "movimentos sociais" e "manifestações" foram usadas. A metodologia aplicada é a análise interpretativa, a partir da Teoria das Representações de Serge Moscovici. O que se observa, em síntese, é que as revoltas estudantis de 1968 são recorrentemente lembradas, como referência histórica em tempos atuais, servindo para tornar familiar os fenômenos dos movimentos sociais que tomam de assalto a sociedade "adulta".

Palavras-chave: Comunicação. Juventude. Movimentos sociais

\begin{abstract}
This article aims to analyze media representations of youths who protested in the streets of Brazil in three important political moments, dated in 1968, 1988-1992 and 2013. A desk research collected magazine and newspaper articles, O Globo e Veja respectively, which were chosen because they are the largest vehicles in circulation in all periods. The ten reports were found from searches in the digital collections available on the internet, where keywords such as "youth", "revolt", "social movements" and "demonstration" were used. The applied methodology is the interpretative analysis from the Theory of Social Representations of Serge Moscovici. It was observed that the student revolts of 1968 are repeatedly reminded, as a historical reference in modern times, serving to become familiar the phenomena of social movements which storm "adult" society.
\end{abstract}

Keywords: Communication. Youth. Social movements.

\section{Introdução}

Eu vejo o futuro repetir o passado/ Eu vejo um museu de grandes novidades. O tempo não para. (Letra da música "O tempo não para", Cazuza, 1989). 
Este artigo tem por objetivo analisar as representações midiáticas das juventudes que se manifestaram pelas ruas do Brasil em três importantes momentos políticos, datados em 1968, 1988-1992 e 2013. Através de uma pesquisa documental, foram reunidas, para o corpus do presente trabalho, matérias de revista e jornal, Veja e O Globo, respectivamente. Uma revisão de literatura contempla, entre outros, autores que discutem as relações entre a condição juvenil, os movimentos sociais e a sociedade, como Schmuel Eisenstadt (1968), que se debruçou sobre a forma como os jovens se organizam e dialogam com as demandas do mundo adulto, ou Eric Hobsbawn (1995) e Edgar Morin (2006), que desenham a trajetória da juventude na eclosão das mudanças sociais de meados do século XX, e ainda Pierre Bourdieu (1983) e Stuart Hall e Kathryn Woodward(2000), os quais, cada um a seu termo, contribuem para a compreensão das possibilidades de construção dos seus espaços de pertencimento e identidade.

É, sobretudo, nas sociedades ocidentais que se reservam espaços de centralidade aos jovens, processo que se intensificou, principalmente, em meados dos anos 1950, com a consolidação da cultura de massa. A internacionalização da música e do cinema norte-americanos, invocando a transgressão e a rebeldia como marcas definitivas da juventude, incrementou um mercado consumidor que rapidamente se expandiu pela América do Sul e Europa, num primeiro momento, e depois para os países asiáticos (Morin, 2006). Pelas vias do consumo, a juventude estabeleceu seu lugar na sociedade, tanto como consumidor, quanto como influenciador. Mais ainda, o consumo fez do jovem seu mais explícito objeto. A juvenilização da vida cotidiana expande a ideia de juventude para todas as faixas etárias, e consomem-se, simbolicamente, seus valores, suas práticas e, concretamente, os bens materiais a ele relacionados. Trata-se, antes, de uma maneira de controlar o que foge do controle, o que excede os limites socialmente concedidos para o exercício de sua liberdade uma espécie de licença para errar, experimentar, arriscar e transgredir, mas em que os riscos - assumidos pelos adultos - são bem calculados.

\section{Breve nota teórico-metodológica}

Alguns estudos do campo da Comunicação que, com maior ou menor densidade, se voltam para a análise das representações sociais, tendem a uma abordagem interpretativa. Nada de errado, até aqui, considerando que, por princípio, o cientista social é, antes de tudo, o sujeito que observa, descreve e interpreta as sociedades. Clifford Geertz (1989), com sua "interpretação das 
culturas", nos apresentou a uma nova abordagem antropológica de um outro ponto de vista, qual seja, o do nativo. Isso, porém, sem desprezar o caráter subjetivo do observador. Pierre Bourdieu (1999) levantou importantes questões sobre o ofício do etnógrafo e discutiu a necessidade de se exercitar sempre a "reflexividade científica". A interpretação é, portanto, característica inerente às ciências sociais de um modo geral.

O problema que se apresenta aqui é outro. Novamente, a "reflexividade científica" de Bourdieu (1999) - exercício permanente do distanciamento do objeto de estudo e afirmação do lugar neutro do observador - sublinha os riscos aos quais, como autores, nos submetemos, diante da enorme tentação que se coloca: a do abandono da teoria e a da posse ilegítima de uma leviana liberdade interpretativa. Em nome da cientificidade, sobretudo, é pertinente que se aponte a que se refere o fenômeno das representações sociais; mais ainda, é de enorme contribuição para as ciências sociais propor metodologias que aproximem as teorias das representações sociais da prática da pesquisa em si, seja ela de campo ou documental.

Quando aqui se faz referência ao "fenômeno das representações sociais", está-se invocando, por definição, a teoria que baliza este estudo, entre outras possíveis a serem acessadas, que procuram construir um conhecimento sobre o tema em questão. Trata-se da teoria segundo Serge Moscovici (2011), para quem, com efeito, as representações sociais - imagens, construções coletivas, classe geral de ideias e crenças - são um "fenômeno" e não um "conceito". O que tal definição delineia é uma das divergências deste autor, referência no campo da Psicologia Social, para com aquele que o inspira, Émile Durkheim, que oferece sua contribuição seminal à Sociologia quando cria os conceitos de "representação individual" e "representação coletiva" (Durkheim, 1970). Sendo fenômeno - produto e efeito da interação social - pressupõe uma dinâmica que carece na ideia de conceito - imposição estática e coercitiva. Moscovici (2011) assume que:

Pessoas e grupos criam representações no decurso da comunicação e da cooperação. Representações, obviamente, não são criadas por um indivíduo isoladamente. Uma vez criadas, contudo, elas adquirem vida própria, circulam, se encontram, se atraem e se repelem e dão oportunidade ao nascimento de novas representações, enquanto velhas representações morrem. Como conseqüência disso, para se compreender e explicar uma representação, é necessário começar com aquela, ou aquelas, das quais ela nasceu (Moscovici, 2011, p. 41). 
Ao propor que a necessidade de se buscar a representação original, se assim podemos nos referir, aquela que deu origem a todas as outras, o autor baseia-se na afirmação de que as representações sociais procuram "tornar familiar algo não familiar, ou a própria familiaridade" (Moscovici, 2011, p. 54). Para ele, há "universos consensuais" que conferem uma espécie de segurança e harmonia no plano das ideias e do conhecimento, que se consolidam com a repetição de situações, gestos e ideias.

\begin{abstract}
Emseu todo, a dinâmica das relações é uma dinâmica de familiarização, onde os objetos, pessoas e acontecimentos são percebidos e compreendidos em relação a prévios encontros e paradigmas. Como resultado disso, a memória prevalece sobre a dedução, o passado sobre o presente, a resposta sobre o estímulo, e as imagens sobre a "realidade" (Moscovici, 2011, p. 55).
\end{abstract}

A teoria de Moscovici inspira o presente trabalho no momento em que motiva a busca por esta espécie de "elo perdido", no "exato momento" em que surgiu, aquele que une o não-familiar ao familiar - deste ambiente consensual onde habitam as representações sociais, inclusive aquelas que conformam o que entendemos por "juventude".

Assume-se, evidentemente, que não há "um" contexto em que se cria a familiaridade. Trata-se de um processo, longo e complexo, e é ingênuo acreditar que a pesquisa documental poderá revelar o "momento exato em que ela emerge na esfera social". Particularmente com relação ao objeto desta pesquisa, a noção de juventude em seu sentido mais amplo, é problemático acreditar que já houve contextos sociais, um que fosse, que prescindisse de sua existência. No entanto, é possível afirmar que está datada a criação da cultura de massa. E é para esta juventude, ou melhor, para a cultura juvenil que nasce com a cultura de massa, que se voltam as observações e reflexões aqui propostas. A contribuição de Moscovici, enfim, está, principalmente, na perspectiva de uma representação social que se constrói coletivamente, a partir de diferentes espaços do mundo cotidiano, inclusive o midiático, cimentando o social, reafirmando a força da memória, buscando a familiaridade e estimulada pelo momento mesmo em que a não familiaridade insurge-se, ainda que momentaneamente, contra o que está posto - para, em seguida, ser modificada, aproximada, identificada e, finalmente, vencida por força da necessidade de um universo consensual.

Assim é que, portanto, este trabalho seleciona diferentes contextos históricos reproduzidos pela mídia para serem analisados como parte das representações sociais que servem a esta dinâmica, em que, 
[...] ao ocorrer uma brecha ou uma rachadura no que é geralmente percebido como normal, nossas mentes curem a ferida e consertem por dentro o que se deu por fora. Tal processo nos confirma e nos conforta; restabelece um sentido de continuidade no grupo ou no indivíduo ameaçado com descontinuidade e falta de sentido (Moscovici, 2011, p. 59).

Pela mídia, sobretudo, emergem esses processos de "cura" ou, de outro modo, de "rachadura". Pelas lentes que aqui se aplicam, o que ameaça é a força transgressora dos jovens: antes, deve-se perguntar, desde quando ela é transgressora? Por que cabe aos jovens a licença para fazerem irromper as rupturas e rachaduras? Qual é, enfim, a relação de forças que se estabelece entre a cultura midiática e a cultura juvenil, a partir da abordagem moscoviciana das representações sociais?

\section{Rebeldia e alteridade}

A escolha das revoltas estudantis de 1968, no Brasil, como ponto de partida da análise comparativa que aqui se propõe é, a partir de Moscovici, uma escolha metodológica no sentido de buscar, no tempo histórico, os fatos que, por sua não familiaridade, suscitaram as representações sociais da noção de juventude, tais quais as entendemos hoje.

Naquele momento, na França e em outros países do mundo, novos acontecimentos levavam às ruas atores que, antes, não se faziam notar na esfera política e social mundial. No Brasil, não foi diferente. Através da interação entre pessoas e grupos, do cotidiano das trocas, e também dos discursos da mídia, entre outros agentes, todos, enfim, colaboraram para que aqueles estudantes que espantaram e incomodaram a ordem estabelecida, e que, por um momento, não eram identificados como parte da juventude que até então se fazia conhecer, passassem a habitar o tão necessário "universo consensual" (Moscovici, 2011) das sociedades.

Era preciso, então, que, rapidamente, se enquadrasse aqueles jovens dentro de um repertório dado, historicamente repetido. O modo mais imediatista era encontrar, em suas ações, manifestações relacionadas ao momento, digamos, hormonal e psicológico, decorrentes da fase biológica da vida pela qual passavam. Pois que já se reconhecia, nos adolescentes e jovens, uma forte tendência a atitudes impensadas e arriscadas, reações "naturais" às mudanças que aconteciam em seus corpos. Com o tempo, os estudantes rebeldes de 1968 passaram a figurar entre possíveis tipos de juventude e a fazer parte, portanto, do 
"ambiente consensual" (Moscovici, 2011) das sociedades modernas ocidentais daquele contexto.

No final dos anos 1980, e depois nos anos 2000, por consequência, os movimentos sociais protagonizados pelos jovens também precisavam ser "familiarizados"; e o modelo reconhecido de juventude rebelde anterior àqueles era o de 1968, o que levou às representações sociais que dele os aproximavam ou distanciavam, comparativamente. Pelas matérias jornalísticas mais adiante apresentadas, selecionadas destes três períodos históricos, será possível discutir este processo de construção das representações sociais de dois aspectos da noção de juventude pela mídia, a rebeldia e a alteridade.

Eric Hobsbawn (1995), ao tratar da "revolução social" do período entre 1945 a 1990, em seu "breve século XX", aponta o esvaziamento do campo no pós-guerra e, consequentemente, o surgimento de um "novo fator na cultura e na política" das grandes cidades industrializadas, subitamente povoadas pela migração dos camponeses, dentre eles, "massas de rapazes e moças e seus professores, contadas aos milhões ou pelo menos centenas de milhares em todos os Estados, a não ser nos muito pequenos atrasados, e concentradas em campi ou 'cidades universitárias' grandes e muitas vezes isolados" (Hobsbawn, 1995, p. 292). Bourdieu e Passeron (1968 [1964]), baseados em pesquisa de campo realizada nas universidades, refletem sobre o lugar destes jovens na sociedade francesa daquele contexto. Segundo os autores, a vida no campus e ocotidiano das aulas levam a uma maneira muito particular de lidar com o tempo e com o espaço. Para esses autores, lazer e trabalho se misturam, levando os jovens universitários a desenharem seus dias a partir de suas vontades e desejos. Consequentemente, ainda segundo Bourdieu e Passeron, os estudantes observados naquele início dos anos 1960 não constituíam um grupo: "Tudo conduz então a duvidar que os estudantes constituem de fato um grupo social homogêneo, independente e integrado [...]" (Bourdieu; Passeron, 1968 [1964], p. 68).

Havia, no entanto, ainda segundo os autores, uma "vontade de realizar, tanto no mito da unidade como no jogo da diversificação, a identificação individual a alguma coisa que, sem ser um modelo, é menos que um ideal e mais que um estereótipo, e que define uma essência histórica do estudante" (Bourdieu; Passeron, 1968 [1964], p. 70-71). Nas entrevistas realizadas pelos dois pesquisadores, os entrevistados de vinte e poucos anos afirmavam que não se percebiam como um estudante nos moldes do que se espera, no senso comum. Havia, com efeito, uma representação social do estudante que seguia uma corrente intelectual, ou que frequentava solitariamente cafés, ou do "estudante 
sorboniano", com "semblante carregado", que lê Le Monde e que critica sua própria universidade.

No entanto, os universitários entrevistados por Bourdieu e Passeron não se identificavam com este modelo típico ideal, mas todos buscavam "transfigurar", usando a expressão dos próprios autores, "a necessidade em liberdade". De se libertar de qualquer tipo de autoridade e, antes, da autoridade familiar. Romper com os valores da burguesia, de onde vinha, segundo os autores, a maioria dos universitários franceses pesquisados. Ao mesmo tempo, sentiam outra necessidade, a de diferenciação. A diferenciação pela diferenciação. Por consequência, formavam-se vários grupos que se constituíam a partir de afinidades filosóficas, estéticas ou políticas, e que se opunham entre si; estudantes de esquerda que recusavam filiações partidárias e que manifestavam suas convicções por novos rótulos, como "trotskismo renovado", "anarquismo construtivo", "neocomunismo revolucionário" (Bourdieu; Passeron, 1968 [1964], p. 78-79), entre outros. Expressava-se, ali, a necessidade de se diferenciar, mas, sobretudo, a necessidade de romper com todo e qualquer tipo de limite.

No momento em que Bourdieu e Passeron realizaram suas pesquisas na França, conclui-se, parecia impossível o que se sucederia quatro anos depois, nas ruas de Paris, dada a fragmentação deste ambiente universitário, em sua diversidade e diferenciação. O que, então, levaria à integração que lhes faltava, para que se reconhecessem, enfim, como um grupo?

Eram, segundo Hobsbawn, milhões de jovens que, de repente, foram "despejados nas universidades e instituições que não estavam física, organizacional e intelectualmente preparadas para tal influxo"(Hobsbawn, 1995, p. 295), surgindo, consequentemente, uma "inevitável tensão entre essa massa de estudantes", muitos deles sem dinheiro, que se viam diante das limitações impostas pelas universidades, deixando-os ressentidos: "O ressentimento contra um tipo de autoridade, a universidade, ampliava-se facilmente para o ressentimento contra qualquer tipo de autoridade e, portanto (no Ocidente), inclinava os estudantes para a esquerda" (Hobsbawn, 1995, p. 295).

Tratava-se de um grupo que não havia passado pela guerra e que, portanto, não tinha a experiência de seus pais e avós, dos "tempos de aperto e desemprego". A falta de experiência, ou ao menos daquela experiência que marcou toda uma geração, criou um hiato entre pais e filhos. Uma distância que, segundo Hobsbawn, foi um dos traços mais marcantes da "revolução cultural" que modificaria o sentido de instituições como a família, a estrutura mesma das relações entre os sexos e as gerações. Os jovens da segunda metade dos anos 1960 estavam do lado oposto dos adultos, uma alteridade que passou a existir 
também por motivações sociais, e não mais "hormonais". Para o historiador, esta luta não era apenas pela "liberação social", mas principalmente pela "liberação pessoal" (Hobsbawn, 1995, p. 326). Desejo e política se misturavam e se expressavam em slogans como "Quando penso em revolução quero fazer amor", "O pessoal é político", “É proibido proibir", "Tomo meus desejos por realidade, pois acredito na realidade dos meus desejos" (Hobsbawn, 1995, p. 325-326).

Considerando a contribuição de Hobsbawn até aqui, pode-se assumir que a juventude de 1968 traz novas (não familiares, remetendo mais uma vez a Moscovici) nuances para antigas representações sociais já sedimentadas. A ideia de que os jovens carregam a rebeldia e a tendência à contestação dos valores adultos não era nova naquele momento. Ao contrário, como demonstra Hobsbawn, "os grupos jovens, ainda não assentados na idade adulta estabelecida, são o locus tradicional da alegria, motim e desordem, como sabiam até mesmo os reitores de universidades medievais, e as paixões revolucionárias são mais comuns aos dezoito anos que aos 35" (Hobsbawn, 1995, p. 294).

Os estudantes de 1968 modificaram esta noção, contudo, no momento em que passaram a ser vistos como uma massa e, pela primeira vez, como um grupo que tem um espaço físico e simbólico importante, naquele momento: a universidade - ainda que, como afirmamos antes, a partir de Bourdieu e Passeron, tal espaço não fosse, automaticamente, indicativo de integridade. Mais ainda, suas revoltas foram organizadas, ganharam concretude e, por sua efetividade, contagiaram outros setores da sociedade. Era um novo agente social que ameaçava a ordem, pela primeira vez, com força - física e moral. Jovens que não somente contestavam os valores vigentes, mas propunham novos. Havia ali um projeto global que, por circunstâncias, viu-se alinhado às ideologias de esquerda, ainda que, muito rapidamente, viesse a romper com as instituições partidárias "adultas". Era um movimento de jovens que, pela primeira vez, não estavam movidos apenas pela paixão: havia uma organização.

Shmuel Eisenstadt (1968 [1956]) debruça-se sobre as organizações juvenis nas sociedades modernas e apresenta dois principais: "grupos informais" e "movimentos juvenis voluntários". Por "grupos informais", Eisenstadt entende grupos pré-adolescentes e adolescentes que se formam graças a uma dada proximidade, que pode ser geográfica (moradores do mesmo bairro) ou formal (filiados a alguma organização, como escola, partido político, religião ou time esportivo, entre outros). O que caracteriza a informalidade, porém, é a rejeição a uma liderança central, de cima para baixo, e determinados "valores", que variam de acordo com o contexto sociocultural: entre os adolescentes de classes médias, são eles, os esportes, “a participação social, a lealdade do grupo e a realização 
e responsabilidade individual" (Eisenstadt, 1968 [1956], p. 15). Há, segundo ele, uma forte relação entre os valores destes jovens e os de seus estratos sociais, porém, evidencia-se uma ambivalência e antagonismo em relação ao mundo adulto, o que os torna "irresponsáveis", hedonistas etc. De modo diferente, os grupos juvenis de camadas sociais mais pobres acabam reproduzindo os valores adultos, embora sejam mais autônomos de "organizações patrocinadas por adultos (escotismo, clubes etc.)" do que os anteriores. Eisenstadt menciona, ainda, as gangs, grupos de delinquentes juvenis, que violam a ordem, os costumes e as normas da sociedade, aproximando-se, pela transgressão, dos grupos de classe média.

Por "movimentos juvenis voluntários", o autor define aqueles em que a adesão é voluntária, em que há filiação a organizações "adultas" (ideológicas, políticas, profissionais etc.), e uma formação estruturada, hierarquizada e ritualizada. A ambivalência que os distancia do mundo adulto se dá de uma maneira diferente daquela dos "grupos informais", já que buscam alcançar e disseminar valores os quais não são mais encontrados no mundo adulto "contaminado". Ainda que tais movimentos sejam, como foi dito, filiados a organizações adultas, sendo leais às suas causas, eles não aceitam sua liderança, assumindo este lugar aqueles jovens um pouco mais velhos.

No Dicionário Houaiss, rebelde é aquele que "não se submete, não acata ordem ou disciplina; insubordinado"; outros sinônimos para a palavra rebeldia podem ser "oposição" ou "teimosia". A ordem e a disciplina, de um determinado ponto de vista (hegemônico adulto), são resultado da tentativa, do erro e do acerto. A insubordinação ao que está estabelecido e a teimosia, portanto, são a negação da experiência; ao mesmo tempo, é por causa da inexperiência que os jovens se aventuram por caminhos arriscados, buscam novas possibilidades, propõem revoluções. E contribuem, desta forma, para as mudanças, sempre necessárias. A submissão e a oposição estão dadas, evidentemente, e referemse às gerações anteriores, àqueles que constroem, para esses jovens, um mundo que poderia, afinal de contas, ser bem melhor. E só pode ser desta forma porque há uma oposição, um Outro - aquele que acumula experiência e poder, impondo disciplina e, ao mesmo tempo, fazendo uso da insubordinação alheia para avançar.

Rebeldia e alteridade, como se vê, são ideias que se complementam, no contexto da presente discussão. E encontram-se, esses dois eixos, na noção de juventude. 


\section{Demarcando fronteiras: rebeldia}

"A rebeldia é um traço saudável da juventude; quando um pai e um filho nunca brigam, é porque um dos dois não está levando uma vida normal", afirmou Roger, vocalista da banda Ultraje a Rigor (O Globo, 22/09/1985, p. 7), um dos ícones da cultura juvenil brasileira nos anos 1980. A rebeldia, para além de ser uma marca da juventude, é um demarcador de fronteiras, é uma espécie de chave para compreender o outro tema que, relacionado aos jovens, sustenta as reflexões deste artigo: a alteridade, a qual é determinante para estabelecer as diferenças e oposições e, por consequência, a identidade e o sentimento de grupo.

Como discutido anteriormente, a geração de 1968 é, na mídia, a referência mais recorrente para descrever outras que a sucederam, como forma de tornar o não conhecido em conhecido, como afirma Moscovici (2011), por força de um "ambiente consensual", de harmonia de significados e de representações sociais "familiares". Ela é, portanto, aquela que confere familiaridade a este jovem que sai às ruas entre 1988 e 1992, e em 2013. Estabelece-se, assim, uma comparação direta. E, para serem reconhecidos como grupo, recorre-se a símbolos culturais, como o vestuário ou a música:

\footnotetext{
Eles já não usam mais calças boca-de-sino nem blusas cacharrel e não têm como música-tema "Pra não dizer que não falei de flores", de Geraldo Vandré. Eles também não falam da esquerda como bandeira e a grande maioria chega a fazer questão de esclarecer que não está ligada a qualquer partido político. [...]Eles têm entre 12 e 17 anos, são irreverentes e descontraídos, usam lencinhos amarrados na cabeça e bermudas - propositalmente - rasgadas. Vencidos alguns quilômetros, não se sentem culpados por parar num bar e matar a sede com uma cervejinha gelada (O Globo, 25/08/1989, p. 12).
}

A rebeldia, porém, tem nuances e níveis. Há uma clara referência a uma dada autenticidade dos rebeldes de 1968, que, afinal, empreenderam uma "incrível batalha", com bandeira em punho e música de protesto; aos anjos rebeldes de 1989, "irreverentes e descontraídos", que parecem se preocupar mais com a roupa que usam do que com a motivação que os leva a protestar; e os que, simplesmente, não têm uma causa:

[...] nos últimos dias, contudo, boa parte dos manifestantes não é usuária de ônibus. Por que direitos eles vociferam, então? A história recente mostra que, mesmo quando nem eles sabem exatamente por que se rebelam, os jovens, quando vão às ruas protestar, precisam ser ouvidos [...] (Veja, 19/06/2013, p. 92). 
Enquanto aqueles do final dos anos 1980 participam da manifestação de bermudas "propositalmente" rasgadas, e também param para se divertir e"matar a sede com uma cervejinha gelada", esses de 2013 protestam contra o aumento da passagem de ônibus que, na verdade, eles nem usam: "A tentação maior é rotulá-los de rebeldes sem causa, bem ao estilo do personagem da música dos anos 80 do grupo Ultraje a Rigor, aquele garoto que os pais 'tratam muito bem' e que recebe deles 'apoio moral' e 'dinheiro pra gastar com a mulherada'" (Veja, 19/06/2013, p. 88). Há, neste discurso, um esforço de deslegitimação dos referidos movimentos sociais, e isso acontece graças à comparação com o que seria legítimo por direito, ou seja, as primeiras revoltas estudantis, 45 anos antes.

Os jovens de 1968 estão na capa da quinta edição da revista Veja, de 9 de outubro de 1968 (Figura 1). Nela, aparecem correndo em meio ao fogo ateado na rua. Eles são tratados como "estudantes" e seus protestos são pautados por "batalhas". Por outro lado, os do final dos anos 1980, ao contrário, são considerados pacíficos e nem chegam a ser reprimidos, pois parecem não oferecer qualquer ameaça à polícia, a não ser pelo trânsito que provocam: "Uma das provas do pacifismo dos manifestantes é a atitude da Polícia, que se limita a organizar o trânsito e garantir a integridade física dos estudantes, sem reprimilos, porque não é provocada por atitudes radicais" (O Globo, 10/04/1988, p. 18). Com efeito, eles são chamados, na capa da revista Veja, de "anjos rebeldes".

- Figura 1 - Revolta e rebeldia na capa da revista Veja

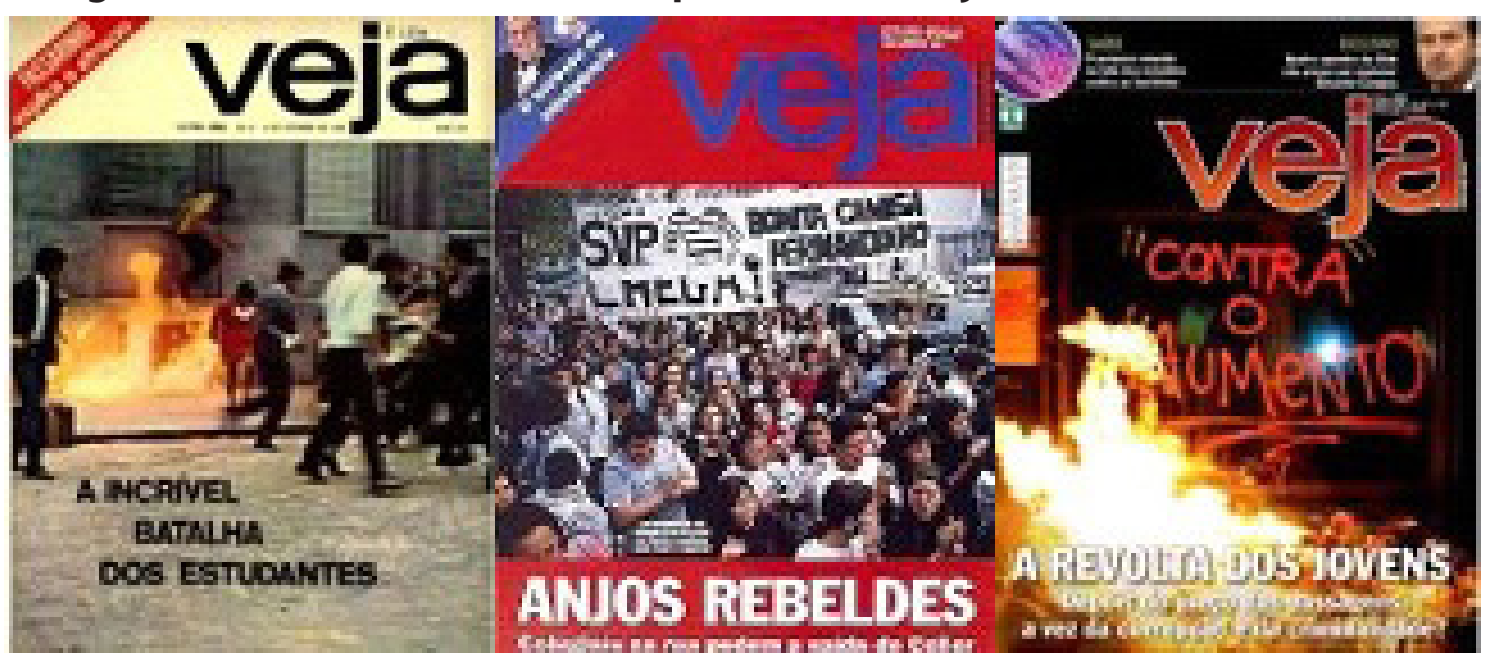

Fonte: Revista Veja, 9 de outubro de 1968; Revista Veja, 19 de agosto de 1992; Revista Veja, 19 de junho de 2013. 
Na revista Veja de 2013, a violência ressurge na capa da edição de junho, assemelhando-se muito com aquela de 1968: explosiva, incendiária, perigosa. A batalha, a rebeldia e a revolta são propriedade dos jovens, pertencem a este mundo, a um mundo de risco e transgressão; em oposição ao mundo adulto, da ordem e do controle. A rebeldia é, portanto, a marca desta fronteira que separa o jovem do adulto: “Uma vítima? Para a polícia, apenas uma agressora que perdeu sua guerra" (Veja, 11/09/1968, p. 22). Rivalizam-se os dois lados, vitimizam-se e acusam-se mutuamente, mas, acima de tudo, estabelecem-se como opostos estudante x polícia; jovem x adulto: “Quem jogou a primeira pedra, os moços ou a polícia? Os dois lados admitem a violência" (Veja, 11/09/1968, p. 22). Também nas manifestações mais recentes, a polícia e os jovens colocam-se como duas faces da mesma moeda - a violência de uma incita a necessidade de expressão pela rebeldia, dos outros: "Com a violência policial, os manifestantes passam a marchar pelo direito de se manifestar" (O Globo, 18/06/2013, p. 13).

Evocando, mais uma vez, Bourdieu e Passeron (1968 [1964]) e Eisenstadt (1968 [1956]), os jovens recusam a autoridade adulta. A própria ideia de rebeldia, portanto, leva à oposição: se rebeldia é sinônimo de insubordinação, assumese que há o sujeito que se impõe e subordina, e um outro que é subordinado. A oposição entre jovens e adultos passa, portanto, pela ideia de rebeldia, tão enfatizada nas representações midiáticas da juventude.

\section{Coração e cérebro: alteridade}

As categorias "jovem" e "adulto", embora sejam apenas duas das outras possíveis relacionadas às fases da vida biológica de um indivíduo - criança, préadolescente, adolescente, velho são outras possíveis - representam, por força simbólica, noções binárias, opostas, referenciais para todos os outros estágios de idade. Como aponta o trecho da matéria publicada no jornal, ao sublinharem a oposição "nós" e "eles", de forma tão explícita:

\footnotetext{
"Eles" são cerca de três mil estudantes secundaristas que, ontem, uniram Zona Norte, Zona Sul e o Centro do Rio numa grande passeata. Enquanto 20 anos atrás eles tomavam as ruas para protestar contra o regime militar, agora o inimigo é outro. O que "eles" não querem é que seus pais continuem a sofrer com os aumentos das mensalidades escolares e pedem que o Governo garanta o ensino gratuito para todos (O Globo, 25/08/1989, p. 12).
} 
Por alteridade, entende-se o reconhecimento de um Outro. Portanto, a ideia de alteridade passa, necessariamente, pela compreensão do que venha a ser "identidade". Para elaborar brevemente este conceito, que mereceria uma análise mais profunda dada a sua complexidade, recorremos Kathryn Woodward (2000) que, pautada nas ideias de Stuart Hall, realiza uma revisão de literatura bastante didática sobre a relação entre identidade e diferença. Para a autora, as identidades ganham sentido na dinâmica social da linguagem e dos sistemas simbólicos os quais as constituem. As representações sociais que daí decorrem ajudam a classificar o mundo, as coisas, os grupos, os indivíduos. A identidade, para Woodward (2000, p. 9) é "relacional", ou seja, só existe porque existe a identidade de um Outro. E, portanto, ela se distingue pelo que "não é": "A identidade é, assim, marcada pela diferença" (Woodward, 2000, p. 9).

A ideia de alteridade que pretendemos aqui sublinhar sustenta-se, portanto, na discussão de Woodward, quando a autora afirma que a ordem social é mantida por meio de oposições binárias, tais como insiders e outsiders. A produção de categorias sociais de acordo com o sistema social vigente garante, assim, um certo controle social. Mais ainda, os dualismos que expressam a diferença são caracterizados por um desequilíbrio de forças, ou seja, há sempre um que é mais valorizado que o outro: "um é a norma e o outro é o 'outro' - visto como 'desviante ou de fora'" (Woodward, 2000, p. 51). "Um” é o adulto e "outro" é o jovem. O adulto é a "norma" e,12 o jovem, o "de fora", "desviante".

A alteridade da juventude universitária dos anos 1960, portanto, se dá graças à oposição com os adultos, e com tudo o que representa o seu lado mais controlador e autoritário. E tal alteridade, tão necessária para a afirmação da unidade entre os universitários, precisa ver-se confrontada com aquilo a que se opõe. De um lado, o estudante; do outro, a polícia (Figura 2). “Estudantes e polícia são como duas moléculas diferentes colocadas uma diante da outra. Elas se atraem, provocam o encontro de energias contrárias e geram o atrito. Se elas fossem iguais, o resultado seria a estabilidade" (Veja, 11/09/1968, p. 22). 
Figura 2 - Polícia e estudante, adultos e jovens: necessária oposição
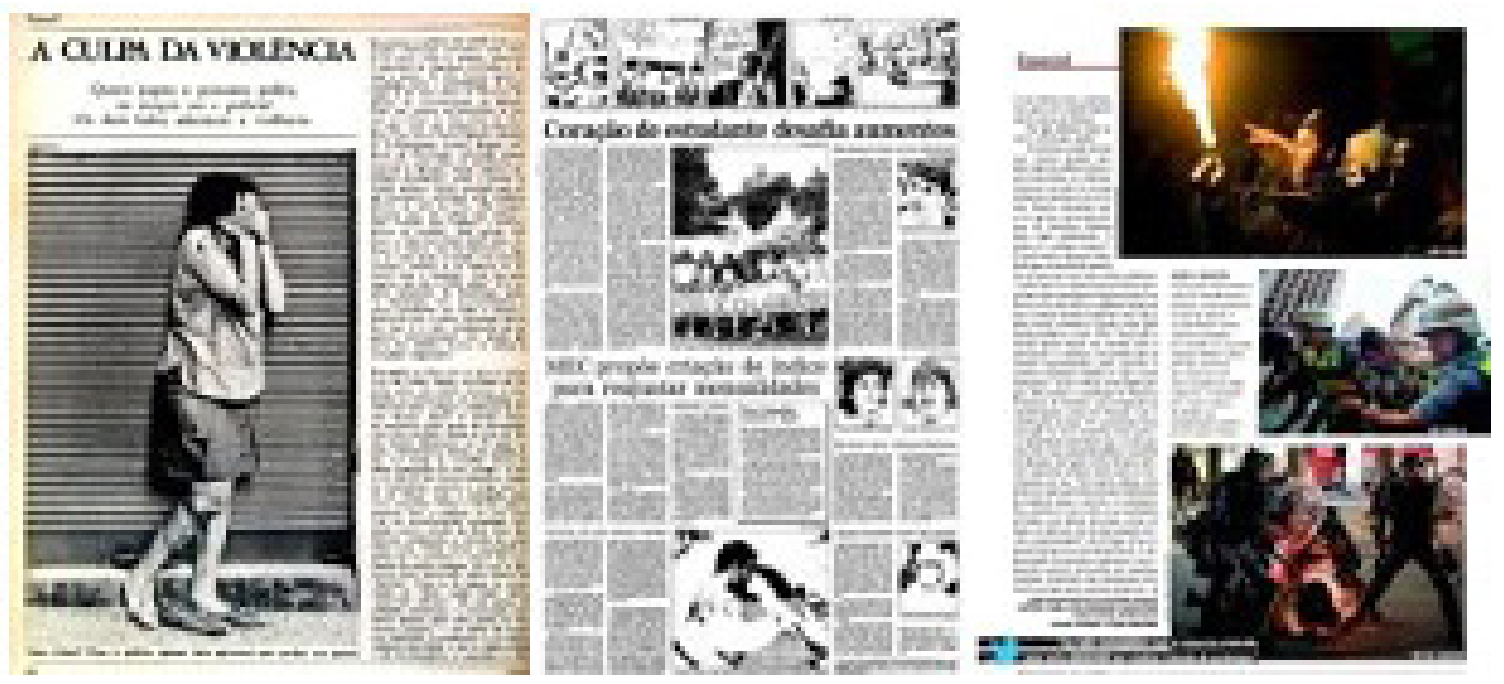

Fonte: Revista Veja, 11 de setembro de 1968; O Globo, 25 de agosto de 1989; Revista Veja, 19 de junho de 2013.

Nesta alteridade em constante construção, o confronto se dá não somente em nome do que está em disputa - as causas, reivindicações, ideologias - mas também em nome dos papéis que são ali exercidos. De um lado, quem disciplina e controla - a polícia; do outro, quem desobedece, transgride, transborda e excede - o estudante. O que está em jogo é a capacidade do autocontrole, portanto. A alteridade se estabelece entre um, que é natureza - o jovem, que não controla suas emoções - e o Outro, que é cultura - ciente das regras, no pleno domínio de seus atos. A "ira" e a "fúria" (Figura 3), portanto, cabem àquele que é natureza; o que não se controla e que, portanto, precisa ser disciplinado.

Figura 3 - Ira, fúria e rebeldia

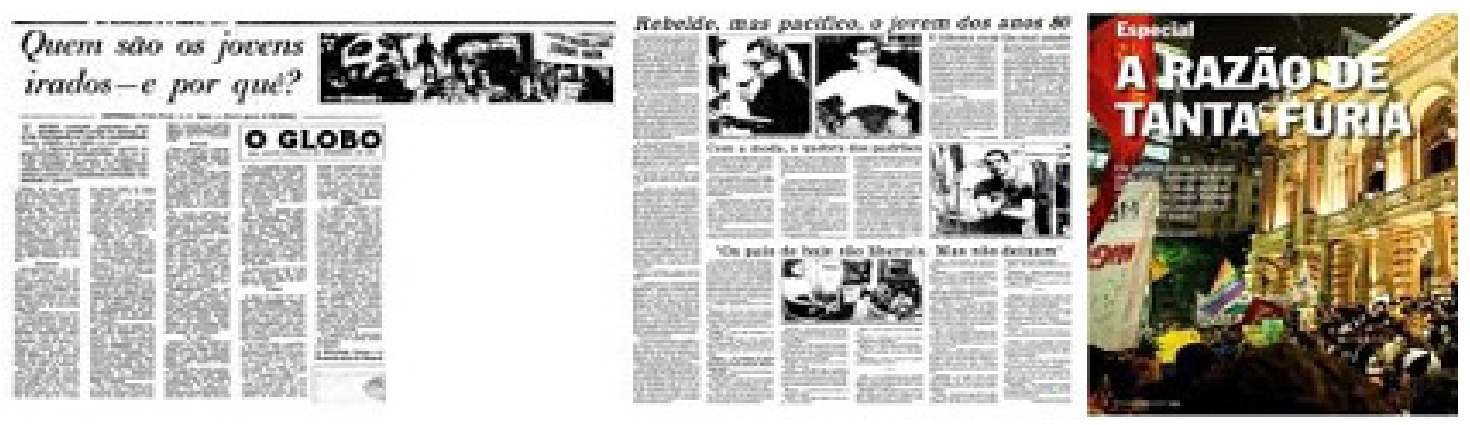

Fonte: O Globo, 2 de dezembro de 1968; O Globo, 22 de setembro de 1985; Revista Veja, 19 de junho de 2013. 
Alfred Jules Ayer, professor e filósofo positivista britânico, em seu artigo ao jornal O Globo (12/12/1968, p. 1), procura explicar"quem são os jovens irados - e por quê". Em seu texto, Ayer (1968) afirma que os fatos noticiados se devem à publicidade feita, nos meios de comunicação, à moda disseminada pelos jovens, que confere a eles uma "unidade artificial". Uma moda que, segundo Ayer, não representa prática da maioria dos jovens que conhece, "que seguem tranquilos com seu trabalho, trilhando um caminho que não será, em essência, diferente do percorrido pelos pais". Trata-se da consciência de uma "cultura jovem", coisa que, para o filósofo, é uma novidade naquela geração. Há, portanto, os jovens que são "vítimas da moda", que acabam por obedecer àqueles que estão à frente desta cultura. Os "velhos", ainda segundo Ayer (1968), são os "bodes expiatórios", são aqueles a quem o jovem deve se opor. Porém, se oporão apenas aqueles que não seguem uma vida de trabalho e disciplina. Neste momento do texto, $\mathrm{o}$ articulista faz uma oposição entre "ciência" e "arte":

É digno de nota que, nos distúrbios ocorridos nas várias universidades, dificilmente se encontraram cientistas entre os manifestantes. De modo geral, o jovem cientista executa um trabalho interessante que acredita de valor; e sabe que se tiver algum mérito, a sociedade pagará bom preço pelos seus serviços. Por outro lado, o estudante de artes, cuja única esperança é conseguir um emprego de professor para o qual talvez não tenha vocação - ou passar seus dias na rotina de um escritório, bem pode achar que o sistema é falho (O Globo, 12/12/1968, p. 1).

De um lado, a razão (cientistas) e, do outro, o pensamento criativo (artistas). Aqueles se aproximam mais de um modelo de juventude comportada e, portanto, que não se deixa levar pelas modas, pela emoção; o Outro, portanto, é o jovem manifestante, que não tem vocação, nem futuro, apenas "ira". Ele é uma vítima e reclama do sistema porque não vê nenhuma possibilidade de êxito na vida profissional.

O mesmo desconforto expresso por Ayer com relação aos "artistas" parece, 17 anos depois, inverter-se. Há uma cobrança implícita no discurso da mídia quanto à mobilização e rebeldia do jovem dos anos 1980 .

O fato é que o tom pacífico da juventude dos anos 80 inquieta os não-jovens. Pesquisas dariam conta de que os jovens de hoje não são rebeldes e tendem ao conservadorismo. Mas que conservadorismo 
se, para eles, o passado jamais servirá de parâmetro? Prudente seria aos que se consideram adultos, abandonarem a pretensão de julgar enquadrar os jovens em pesquisas ou em conceitos mais vulneráveis que o próprio processo da adolescência (O Globo, 22/09/1985, p. 7).

O jornal aponta, em defesa dessa juventude, alguns caminhos para compreendê-la. Recorre, então, a um sociólogo, a um estilista, a um filólogo e aos próprios jovens e adolescentes. O sociólogo explica: "A nova geração não é conflitiva, é calma e serena. São independentes, mesmo do círculo familiar e sabem utilizar a precária economia informal em que vivem. São limpos, alegres, coloridos, embora a caminho de um possível desemprego (O Globo, 22/09/1985, p. 7).

Em contraste com o "artista" que se rebela contra o sistema por falta de perspectivas de trabalho, este dos anos 1980, ao contrário, demonstra uma placidez e tranquilidade que assustam os adultos na mesma medida. Sua irreverência, segundo a matéria, se dá pelo consumo de moda. Eles não se sentem impelidos a se rebelar contra nada porque acreditam num "mundo novo", que virá com o computador e com a tecnologia, os quais não dependem deles para acontecer. São "pragmáticos" e parecem saber mais objetivamente o que buscam.

Nesse momento, temos um alvo para isso [transformar a sociedade]: PC Farias e o presidente, duas pessoas que simbolizam corrupção e cuja punição serviria de exemplo para o país - diz ele [Lidberg Farias, então presidente da UNE], mostrando a praticidade típica da geração que está nas ruas (O Globo, 27/08/1992, Segundo Caderno, p. 4).

Essajuventudeque foiàs ruas, navirada dosanos 1980/1990,édisciplinada, mais racional e se permite se expressar através do consumo. Por esse motivo, não é identificada com o clássico modelo de rebeldia, incomodando e rompendo com o que os adultos esperam dos jovens. Embora inspirados por seus pais não pelo que eles Ihes ensinaram, mas pelo que passa na televisão - aproximamse ameaçadoramente de um modelo conservador e "alienado": "'Anos Rebeldes' [a minissérie exibida pela Rede Globo no mesmo ano] incentivou a ida para as ruas, mas não serviu de guia para as manifestações. E os alienados descobriram sua arma" (O Globo, 27/08/1992, Segundo Caderno, p. 4). Compromete-se, sobretudo, a alteridade necessária para sua própria sobrevivência como grupo, unidade, identidade cultural. 
Em 2013, reverberando a Primavera Árabe que teve início em 2010, voltam às ruas os jovens revolucionários, inflamados e incontroláveis, levados por "pressões hormonais" e por motivações "passageiras". Dá-se, novamente, a oposição entre um e outro.

Há uma grande chance de que boa parte da rapaziada que, na semana passada, foi às ruas esteja apenas dando vazão às pressões hormonais pelo exercício passageiro do socialismo revolucionário. Afinal, como disse Winston Churchill, "se você não é um liberal aos 20, não tem coração e se não se torna um conservador aos 40 não tem cérebro", afirma a Veja (19/06/2013, p. 88).

Coração e cérebro, órgãos que se opõem pela lógica simbólica que suscitam, mas que precisam um do outro para manterem a vida em movimento.

Jovens estão sempre mais expostos aos hormônios em fúria do que adultos. Uma minoria, porém, tal qual aqueles que Ayer observou em 1968: "Mas essa minoria interessa pouco. Ela sempre será minoria, por definição - ou alguém acha viável um país em que a maioria dos cidadãos quebra tudo a sua volta, dia sim, dia não?" (Veja, 19/06/2013, p. 88).

\section{Considerações Finais}

Voltando ao início do texto, logo na epígrafe, anunciamos que o "museu de grandes novidades" da mídia apresenta-nos três juventudes, dentre tantas, que foram às ruas. $\mathrm{O}$ que nos propusemos aqui foi compreender o percurso destas velhas novidades, em que o futuro repete o passado, como um processo mesmo de construção das representações sociais. A juventude foi a categoria escolhida para ser observada e guiar-nos nesta trajetória, apontando aquela de 1968 como a que, recorrentemente, é evocada no sentido de familiarizar os fenômenos dos movimentos sociais que tomam de assalto a sociedade "adulta".

Matérias jornalísticas de três períodos diferentes - 1968, 1988 -1992 e 2013 - são comparadas à luz da teoria das representações sociais, de Serge Moscovici, buscando-se, basicamente, observar o processo de tornar "familiar" o que é "não-familiar". Considera-se, para tanto, "não-familiar" as manifestações políticas das juventudes dos três períodos que, ocupando as ruas de importantes cidades do país, foram tomadas, nos três casos, como uma espécie de rebeldia, fúria e transgressão típicas dos mais jovens. $O$ estranhamento por parte dos "adultos" e, porque não dizer, seu temor diante da enorme força de mobilização que estas juventudes demonstraram publicamente, buscavam, de alguma forma, doreconhecimentode algo "familiar" e, portanto, pouco ameaçador. As 
reportagens analisadas demonstram que as representações sociais, nas décadas de 1960, 1980/1990 e 2000, são, invariavelmente, construídas nas mesmas bases, quais sejam: a típica rebeldia juvenil, o inevitável embate geracional e por fim, as explosões hormonais comuns nesta fase da vida. Além disso, seas primeiras revoltas estudantis foram narradas, com um nítido esforço de deslegitimação, como ações de rebeldia, nos outros dois momentos as manifestações de 1968 foram tomadas como exemplo original e genuíno, por serem, segundo a mídia, mais sérias e politicamente embasadas do que as outras duas.

O que, contudo, os jovens conquistaram na sociedade ocidental moderno-contemporânea nestes últimos 45 anos, além de um lugar legítimo de oposição aos adultos? Será que ainda somos os mesmos, "apesar de termos feito tudo o que fizemos", como diz a música de Belchior? Se somos "como nossos pais", certamente isso se reflete nas representações midiáticas da juventude, que insistem emdeslegitimar os jovens, ao mesmo tempo em que tornam suas ousadias rebeldes belas capas de revista.

\section{REFERÊNCIAS}

AYER, Alfred Jules. Linha renovada. O Globo, Rio de Janeiro, 12 dez. 1968. Geral, p. 1.

BOURDIEU, Pierre; PASSERON, Jean-Claude. O tempo e o espaço no mundo estudantil. In: BRITTO, Sulamita de. Sociologia e Juventude, IV - Os movimentos juvenis. Rio de Janeiro: Zahar Editores, 1968.

BOURDIEU, Pierre. A 'Juventude' é apenas uma palavra. In: Questões de

Sociologia. Rio de Janeiro: Marco Zero, p. 112-121, 1983. . Introdução a uma sociologia reflexiva. In: O Poder Simbólico. São Paulo: Ed. Bertrand Brasil, 1999.

DURKHEIM, Émile. Sociologia e filosofia. Rio de Janeiro e São Paulo: Ed. Forense, 1970.

EISENSTADT, Shmuel. Grupos informais e organizações juvenis nas sociedades modernas. In:BRITTO, Sulamita de. Sociologia e Juventude, IV-Os movimentos juvenis. Rio de Janeiro: Zahar Editores, 1968.

GEERTZ, Clifford. A interpretação das culturas. Rio de Janeiro: LTC, 1989.

HALL, Stuart; WOODWARD, Kathryn. Identidade e diferença: a perspectiva dos estudos culturais. Petrópolis: Editora Vozes, 2000.

HOBSBAWN, Eric. Era dos extremos: o breve século XX - 1914-1991. São Paulo: Companhia das Letras, 1995.

MORIN, Edgar. Cultura de massas no século XX: o espírito do tempo, v. 2, Necrose. Rio 
de Janeiro: Forense Universitária, 2006.

MOSCOVICl, Serge. Representações sociais: investigações em psicologia social. Petrópolis: Vozes, 2011.

WOODWARD, Kathryn. Identidade e diferença: uma introdução teórica e conceitual. In: SILVA, Tomaz Tadeu (org.); HALL, Stuart; WOODWARD, Kathryn. Identidade e diferença: a perspectiva dos estudos culturais. Petrópolis: Editora Vozes, 2000.

Recebido em: 29/10/2015

Aceito em: 23/12/2015

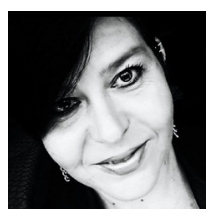

Endereço da autora:

Cláudia da Silva Pereira <caupereira@gmail.com>

http://lattes.cnpq.br/6579798139952341

Programa de Pós-Graduação em Comunicação da PUC-Rio.

Rua Marquês de São Vicente, 225 - Prédio Kennedy - $6^{\circ}$ andar

22453-900 - Gávea - Rio de Janeiro - RJ - Brasil 